\title{
Dual aspect endoscopic evidence of tuberculous bronchoesophageal fistula: successful closure from the esophagus
}

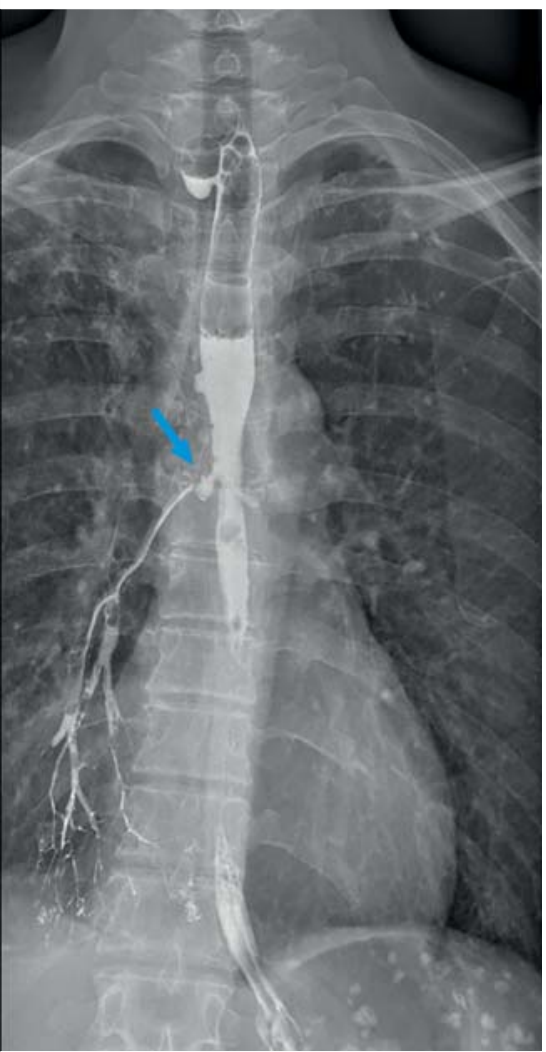

- Fig. 1 Barium swallow evidence of bronchoesophageal fistula (arrow).

Esophageal involvement of tuberculosis is uncommon and two types have been described [1]. Primary esophageal tuberculosis is rare because of mucosal protection factors, squamous epithelium, peristalsis, saliva, and erect posture. Secondary esophageal tuberculosis is more common and is defined as secondary involvement of the esophagus owing to adjacent pulmonary parenchyma, mediastinal lymph nodes, or vertebral column involvement [2].

The development of brochoesophageal fistula (BEF) in tuberculosis is related to mediastinal lymph node involvement; inflammation leads to involvement of neighboring structures, particularly the esophagus and the trachea, resulting in periesophagitis and peritracheitis. If,

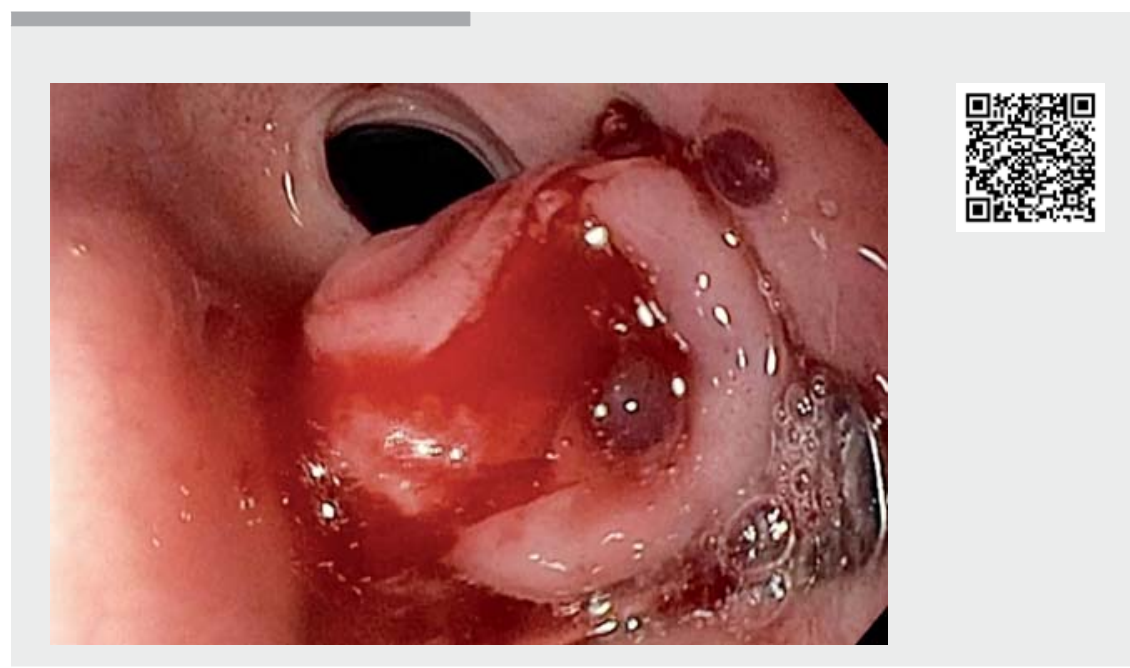

Video 1 Dual aspect endoscopic evidence of bronchoesophageal fistula and subsequent treatment using over-the-scope clip.

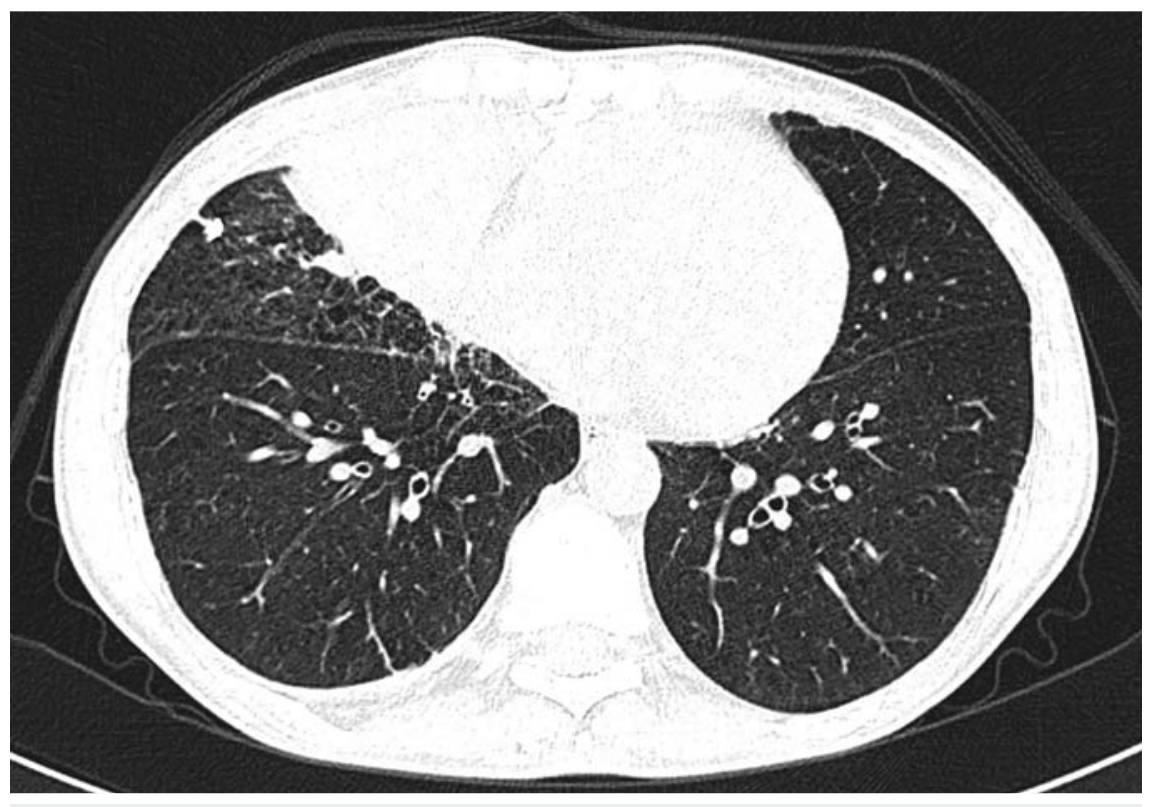

Fig. 2 Computed tomography scan showing middle lobe pneumonia.

however, caseonecrotic lymph nodes rupture, the local abscess formation results in fistula. The most common symptoms of BEF are cough, dysphagia, fever, and pneumonia [2-4].
Antitubercular therapy (ATT) remains a mainstay of treatment. In cases refractory to ATT, further management, including endoscopic interventions and surgery, are needed [5]. 

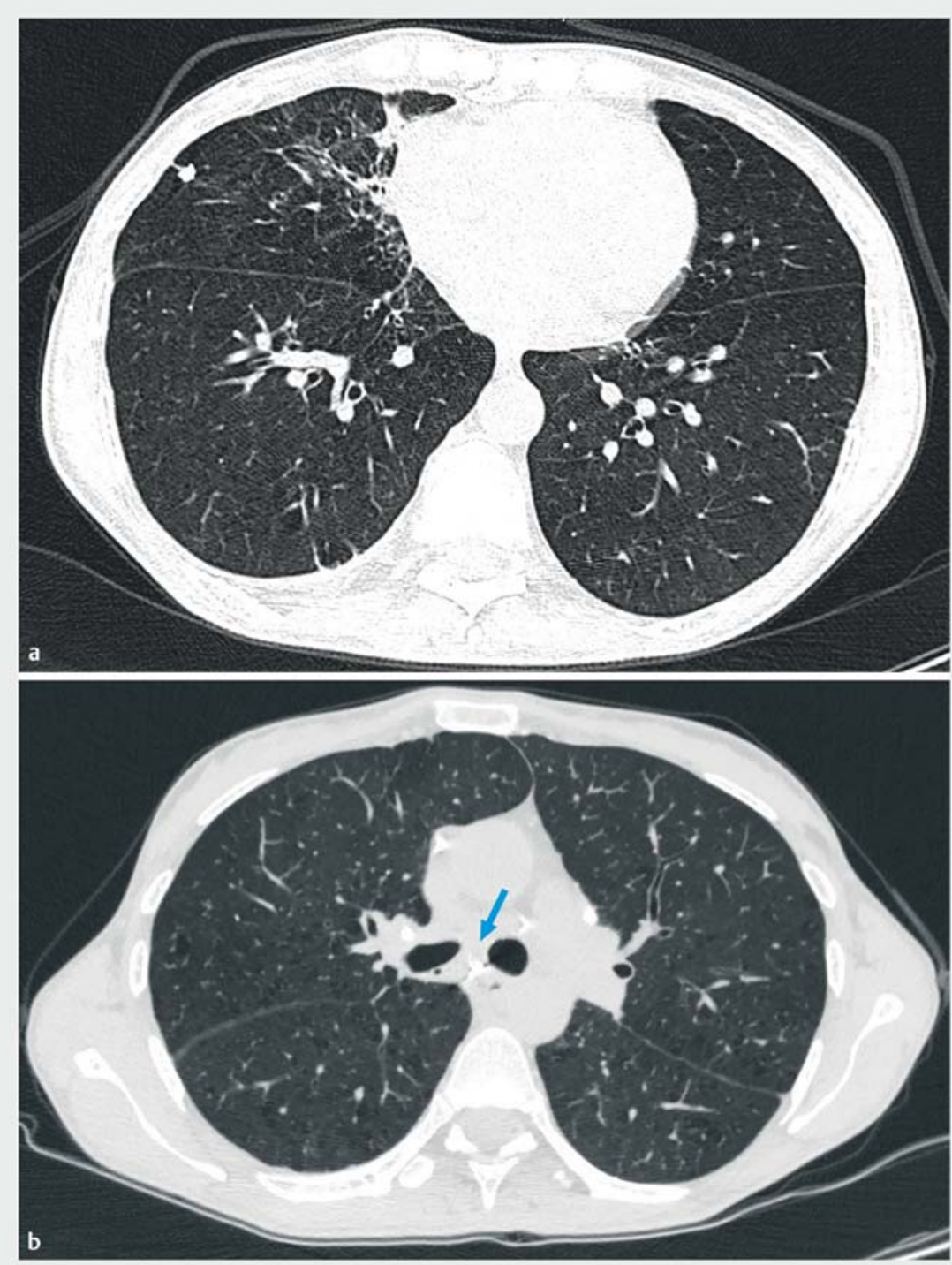

- Fig. 3 Computed tomography at 1-month follow-up. a Significant improvement of middle lobe pneumonia. b Scan confirmed complete fistula closure (arrow).

We report the case of a 47-year-old Caucasian woman, admitted due to weight loss, cough, fever, and dysphagia. She previously underwent ileal resection for tuberculosis involvement and was subsequently treated with ATT, remaining symptom-free until the admission. Barium swallow and chest computed tomography revealed evidence of BEF and middle lobe pneumonia ( Fig. 1, $>$ Fig. 2). The tracheobronchoscopy showed a small anomalous orifice, with a clear pas- sage of mucus, in the medial aspect of the right main stem bronchus. At esophagogastroduodenoscopy, a 1-cm fistula was noted in the middle esophagus. Contrast injection of the esophagus, which leaked into the right bronchus, confirmed the fistula. A 12-mm over-the-scope clip (OTSC; Ovesco, Tübingen, Germany) was placed, and complete fistula closure was confirmed by regular contrast passage through the esophagus without leak ( Video 1). The patient started oral intake on the following day with progressive improvement of symptoms. At 1-month follow-up, no clinical or radiological signs of recurrence were recognized (> Fig. 3 ).

Endoscopy_UCTN_Code_CCL_1AB_2AC_3AZ

\section{Competing interests}

Dr. Bassi has received travel grants from Olympus Italia. Dr. Cennamo is a consultant for and has received speaker fees and travel grants from Olympus Italia, Olympus Europa, Euromedical, and Novità Medicali. All other authors declare that they have no conflict of interest.

The authors

Marco Bassi ${ }^{1}$, Marco Ferrari ${ }^{2}$, Stefania Ghersi ${ }^{1}$, Vanina Livi ${ }^{2,3}$, Emanuele Dabizzi ${ }^{1}$, Rocco Trisolini $^{2,3}{ }^{2}$, Vincenzo Cennamo ${ }^{1}$

1 Gastrointestinal and Interventional Endoscopy Unit, Surgical Department, AUSL Bologna, Bologna, Italy

2 Interventional Pulmonology Unit, Cardiothoracic Department, Policlinico Sant'Orsola-Malpighi, Bologna, Italy

3 Interventional Pulmonology Unit, Dipartimento di Scienze Mediche e Chirurgiche, Università Cattolica del Sacro Cuore di Roma, Rome, Italy

\section{Corresponding author}

\section{Marco Bassi, MD}

Gastrointestinal and Interventional

Endoscopy Unit, Surgical Department, AUSL Bologna, Maggiore Hospital, Largo Nigrisoli 2, 40139 Bologna, Italy Fax: +39-051-6478145 m.bassi@ausl.bologna.it

\section{References}

[1] Lado Lado FL, Golpe Gómez A, Cabarcos Ortíz de Barrón A et al. Bronchoesophageal fistulae secondary to tuberculosis. Respiration 2002; 69: 362-365

[2] Dahale AS, Kumar A, Srivastava S et al. Esophageal tuberculosis: uncommon of common. JGH Open 2018; 2: 34-38 
[3] Park CS, Seo KW, Park CR et al. Case of bronchoesophageal fistula with gastric perforation due to multidrug-resistant tuberculosis. World J Gastrointest Surg 2014; 6: 253-258

[4] Gupta SP, Arora A, Bhargava DK. An unusual presentation of esophageal tuberculosis. Tuber Lung Dis 1992; 73: 174-176

[5] Ni B, Lu X, Gong Q et al. Surgical outcome of esophageal tuberculosis secondary to mediastinal lymphadenitis in adults: experience from single center in China. J Thorac Dis 2013; 5: 498-505

\section{Bibliography}

DOI https://doi.org/10.1055/a-1138-0266

Published online: 27.3.2020

Endoscopy 2020; 52: E378-E380

(c) Georg Thieme Verlag KC

Stuttgart · New York

ISSN 0013-726X

\section{ENDOSCOPY E-VIDEOS}

https://eref.thieme.de/e-videos

口居回 Endoscopy E-Videos is a free access online section, reporting 靣: on interesting cases and new techniques in gastroenterological endoscopy. All papers include a high quality video and all contributions are freely accessible online.

This section has its own submission website at

https://mc.manuscriptcentral.com/e-videos 